\title{
Comparison between the commonly used radiographic techniques for intra oral imaging in dentistry-A questionnaire study
}

\author{
Ramesh Tatapudi ${ }^{1}$, Swathi Myla ${ }^{2 *}$, UpendraGurugubelli ${ }^{3}$, JyothirmaiKoneru ${ }^{4}$, Meenakshi $\mathrm{K}^{3}$, \\ SravaniBandaru ${ }^{2}$, ReshmiThumula ${ }^{2}$ \\ ${ }^{I}$ Professor, Department of Oral Medicine and Radiology \\ ${ }^{2}$ Post Graduate Student, Department of Oral Medicine and Radiology \\ ${ }^{3}$ Senior Lecturer, Department of Oral Medicine and Radiology \\ ${ }^{4}$ Reader, Department of Oral Medicine and Radiology \\ *Corresponding author E-mail:chintaswathi25@gmail.com
}

\begin{abstract}
Aim:-To compare the opinion regarding usage of bisecting-angle technique and the paralleling techniques among BDS students, post graduate students, private practitioners in and around Bhimavaram town for intra oral imaging in dentistry.

Materials and methods: A detailed questionnaire composed of questions regarding technical parameters, exposure parameters, operator and patient comfort and image accuracy in diagnosis. Details of the study were explained to the participants preferred option to be marked according to the question mentioned in the questionnaire. Total 500 individuals participated in the present study, with 100 individuals in each group. Data was collected and entered in Microsoft Excel (2010) and statistically analysed using SPSS 20. Chisquare test was used to evaluate differences in the responses with P-value $\leq 0.05$ were considered significant.

Results: Results showed that in technical parameters most of the people opted for bisecting angle technique with $p$ value $\leq 0.05$ and found as significant. In aspect of exposure parameters, results are in favour of paralleling technique and $p$ value is $\leq 0.05$. In aspect of the operator and patient comfort there is an equal opinion most of them opted for bisecting angle technique and paralleling technique $\mathrm{p}$ value is significant. In aspect of image accuracy $\mathrm{p}$ value is significant for paralleling technique.

Conclusion: Great work should have to be done to alleviate the quality of radiographs and the understanding and perspective of dental graduates regarding dental and maxillo-facial radiology. The results of present study revealed though there is knowledge about the techniques, but lack of application decreases their ability to get more accurate diagnostic radiograph. Paralleling technique being the most accurate in image accuracy should be emphasized to practice and needed to be modified in conditions where it is not feasible to deal with.
\end{abstract}

Keywords: BDS Students; Bisecting-Angle Technique; Exposure Parameters; Image Accuracy; Operator and Patient Comfort; Paralleling Techniques; Post Graduate Students; Private Practioners; and Technical Parameters.

\section{Introduction}

Since the discovery of $x$-rays by roentgen, the dental radiography has evolved as a part with the medical radiology into a valuable aid for diagnosis. With the introduction of digital imaging and the advanced tomography, the diagnosis of oro-facial pathology was possible with millimeter resolution. However, in terms of exposure parameters, ease in availability and their application as a useful screening tool for larger population, within a limited period of time. Periapical radiographs always lie in the main stay (Bramanet CM et al, 1974).

Radiography being a traditional part of dentistry has been considered as one the appropriate method of obtaining information about the tooth anatomy and its surrounding hard tissues. Thus radiographs were considered as third eye to the dentist (Bramanet CM et al, 1974). Radiographs serve a valuable aid in the diagnosis and treatment planning in dentistry. Intraoral periapical radiographic techniques, although have certain limitations and disadvantages, they were not yet replaced by a superior method with similar exposure range. Although the clinical examination is of prime importance, radiographs may provide information concerning Periapical hard tissue, including incipient interdental carious lesions, bone loss in periodontal disease, Periapical pathology and other anatomical and pathological features (Ludlow JB 2004).

For routine clinical use, these intraoral radiographs were usually preferred and the commonly used techniques being the bisecting angle technique (short cone technique) and the paralleling technique (long cone technique). Since this intra, oral radiographs do not require much radiographic exposure, and they were affordable for the patient because of their low cost (Sudhakar S 2014).

Pertaining to the fact that the type of technique to be preferred, when spatial accuracy and reproducibility are prior important, Paralleling technique being a uniform method and should always be preferred (Jamdade AS 2014), It was observed that even though having chances of inherent image distortion, bisecting angle technique is still popular in dental practice owing to its flexibility and ease of performance.

Paralleling technique is most commonly used technique in western countries, but it was not the same with Indian scenario where bisecting angle technique is most preferred (Jamdade AS 
2014). The reasons anticipated were due to lack of practice or usage, because of technical difficulty or may be because of any other reason. Thus present study was intended with an aim to compare the opinion regarding usage of bisecting-angle technique and the paralleling techniques among under graduate dental students. Post graduates from dental students and general dental practitioners.

\section{Methods}

Study was conducted in Vishnu dental college Bhimavaram; private practitioners in and around Bhimavaram town. The Research protocol was approved by the ethical committee of Vishnu dental college and hospital. The research instrument was close ended questionnaire with 20 simple and straight-forwardquestions. These questions were broadly categorized under four factors like image accuracy factors, technical factors, operator and exposure factors and other factors. Questions included in the study sample was divided into five groups based upon their academic levels and time frames of usage of techniques such as Group, I (Third-year year undergraduate students), Group II (Fourth-year year undergraduate students), Group III (Students, who are pursuing intern- ship), Group IV (Post graduates students), and Group V (General dental practitioners). Total 500 individuals were participated in the present study, with 100 individuals in each group. Every participant was explained through the study and those who were willing to participate were included in a present study. Each question had three options 1- Bisecting angle technique 2- Paralleling technique and 3- Other techniques preferred for that particular question. Participants were asked to tick the option preferred. Questionnaire validity and reliability were carried out on a representative sample of dental students who were excluded from the main study. Test Retest was used to check the reliability and internal consistency. The results thus obtained were subjected to statistical analysis. Cronbach's alpha value of 0.81 suggested good internal consisten$\mathrm{cy}$ of the questionnaire. Data was collected and entered in Microsoft Excel (2010) and statistically analysed using SPSS 20 versions. Chi-square test was used to evaluate differences in the responses with $\mathrm{P}$-value $\leq 0.05$ were considered significant.

Results: Out of 500 participated in this study, 100 were third year BDS students; 100 were fourth year BDS students; 100 were students perusing their internship; 100 were post-graduate students, and 100 were general dental practitioners.

Table 1: Questions Included in the Questionnaire

\begin{tabular}{|c|c|}
\hline Factors & Questions involved \\
\hline Image accuracy & $\begin{array}{l}\text { - Which technique has less chances of image distortion } \\
\text { - Which technique is better in appreciating inter-dental and Peri-apical bony changes } \\
\text { - Which technique is better in appreciating dental caries } \\
\text { - Which technique is better in assessment of implants } \\
\text { - Which technique is better in appreciating pathologies of jaws } \\
\text { - Which technique is useful in assessing edentulous condition } \\
\text { canal } \\
\text { Which technique is better to asses working length determination And post-operative assessment of Root canal } \\
\text { treatment } \\
\text { - Which technique is useful in mal-aligned teeth } \\
\text { Which technique has less chances of error while recording radiographs? }\end{array}$ \\
\hline Technical & $\begin{array}{l}\text { - Which technique causes less total body exposure to patient? } \\
\text { - Which technique is easy to modify according to existing condition? } \\
\text { - Which procedure is more technique sensitive? }\end{array}$ \\
\hline $\begin{array}{l}\text { Operator and exposure parame- } \\
\text { ters }\end{array}$ & $\begin{array}{l}\text { - Which technique is more comfortable for the operator? } \\
\text { - Which technique is more comfortable for the patient? } \\
\text { - Which technique do you prefer in your working area? }\end{array}$ \\
\hline Any others & $\begin{array}{l}\text { - Which technique is feasible in mentally challenged individuals? } \\
\text { - Which technique have more chances of infection spread? }\end{array}$ \\
\hline
\end{tabular}

Table 2: Responses of Each Group towards Each Question

\begin{tabular}{|c|c|c|c|c|c|c|c|c|c|c|c|c|c|c|c|c|}
\hline \multirow[t]{2}{*}{ Question no } & \multicolumn{3}{|c|}{ Group 1} & \multicolumn{3}{|c|}{ Group 2} & \multicolumn{3}{|c|}{ Group 3} & \multicolumn{3}{|c|}{ Group 4} & \multicolumn{3}{|c|}{ Group 5} & \multirow[t]{2}{*}{$\mathrm{P}$ value } \\
\hline & $\mathrm{A}$ & B & $\mathrm{C}$ & $\mathrm{A}$ & B & $\mathrm{C}$ & $\mathrm{A}$ & B & $\mathrm{C}$ & $\mathrm{A}$ & B & $\mathrm{C}$ & $\mathrm{A}$ & B & $\mathrm{C}$ & \\
\hline 1 & 20 & 76 & 4 & 40 & 58 & 2 & 79 & 17 & 4 & 15 & 82 & 3 & 23 & 77 & 0 & .000 \\
\hline 2 & 33 & 64 & 3 & 49 & 39 & 12 & 48 & 49 & 3 & 2 & 83 & 15 & 44 & 50 & 6 & .000 \\
\hline 3 & 37 & 58 & 5 & 60 & 40 & 0 & 50 & 50 & 0 & 66 & 31 & 3 & 96 & 4 & 0 & .000 \\
\hline 4 & 45 & 51 & 4 & 53 & 44 & 3 & 62 & 38 & 0 & 28 & 68 & 4 & 32 & 68 & 0 & .000 \\
\hline 5 & 35 & 65 & 0 & 35 & 63 & 2 & 25 & 75 & 0 & 15 & 82 & 3 & 13 & 87 & 0 & .000 \\
\hline 6 & 35 & 65 & 0 & 35 & 63 & 2 & 25 & 75 & 0 & 15 & 82 & 3 & 13 & 87 & 0 & .000 \\
\hline 7 & 24 & 70 & 6 & 50 & 38 & 12 & 54 & 38 & 8 & 37 & 55 & 8 & 10 & 82 & 8 & .000 \\
\hline 9 & 44 & 45 & 11 & 27 & 23 & 50 & 26 & 16 & 58 & 23 & 32 & 45 & 13 & 13 & 74 & .000 \\
\hline 10 & 8 & 44 & 48 & 38 & 24 & 38 & 43 & 17 & 40 & 34 & 20 & 36 & 8 & 44 & 48 & .000 \\
\hline 11 & 34 & 55 & 11 & 55 & 39 & 6 & 60 & 35 & 5 & 29 & 56 & 15 & 10 & 90 & 0 & .000 \\
\hline 12 & 33 & 62 & 5 & 48 & 30 & 22 & 60 & 16 & 24 & 34 & 40 & 26 & 38 & 54 & 8 & .000 \\
\hline 13 & 38 & 51 & 11 & 26 & 38 & 36 & 43 & 29 & 28 & 28 & 40 & 32 & 10 & 74 & 16 & .000 \\
\hline 14 & 18 & 61 & 21 & 59 & 41 & 0 & 84 & 16 & 0 & 48 & 50 & 2 & 66 & 34 & 0 & .000 \\
\hline 15 & 30 & 65 & 5 & 50 & 47 & 3 & 28 & 70 & 2 & 59 & 35 & 6 & 25 & 65 & 10 & .000 \\
\hline 16 & 61 & 31 & 8 & 49 & 43 & 8 & 26 & 60 & 14 & 60 & 34 & 6 & 55 & 45 & 0 & .000 \\
\hline 18 & 30 & 62 & 8 & 33 & 60 & 7 & 45 & 55 & 0 & 38 & 44 & 18 & 32 & 68 & 0 & .000 \\
\hline 19 & 47 & 53 & 0 & 50 & 45 & 5 & 54 & 38 & 8 & 44 & 50 & 6 & 38 & 62 & 0 & .000 \\
\hline 20 & 26 & 70 & 4 & 57 & 37 & 6 & 62 & 38 & 0 & 34 & 62 & 4 & 40 & 60 & 0 & .000 \\
\hline
\end{tabular}

Table 2 shows each group response towards each question and their $p$ values. $P$ values for each question were statistically significant

A - Denotes option bisecting angle technique.

B-Denotes option paralleling technique.

C-- Denotes option other techniques. 


\section{Discussion}

Periapical radiography describes intraoral techniques designed to show individual teeth and the bony structures around the teeth in their apices. Each film usually shows two to four teeth and provides detailed information about the teeth and the surrounding alveolar bone (Whaites E 2002). At routine clinical use the two intraoral radiographic techniques used were the bisecting angle technique and the paralleling techniques (Bragger $U$ 2005).Periapical radiography in practice is not as easy as it appears in theory. A thorough theoretical knowledge helps clinicians in modifying techniques to suit individual patient criteria, since the anatomy of the mouth does not allow rules of geometric projections to be satisfied.

Several studies revealed paralleling technique provides more accurate images than bisecting angle technique. Although paralleling technique is being considered as the technique of choice, practically it may not be always possible to keep the intra oral Periapical film without bending may be due to oral anatomy and patient's intolerance, which renders this technique impossibleto implement in every situation (Langland OF et al, 2002)

On the other hand, bisecting angle technique, which is routinely used in dental practice, was, relatively simple, quickly produces and comfortable to the patient, but it has an inherent drawback of image distortion. Even though having inherent image distortion, bisecting angle technique is still preferred in dental practice because of its resilience. Paralleling technique is a standardized method and should always be preferred when spatial accuracy and reproducibility were desired.

In paralleling technique, the film packet is kept in a film holder and positioned in the oral cavity parallel to the long axis of the tooth for investigation. The anatomy of the palate and shape of arches mean that the tooth and film packet cannot be in parallel and in contact. The film packet is positioned at some distance from the tooth. The X-ray tube head is aimed at right angles both vertically and horizontally to both the tooth and film packet. With the help of the film holder with film packet and X-ray tube head positions, the technique is reproducible.

In bisecting angle technique, the film packet is positioned close to the tooth without bending the packet. The angle formed between the long axis of the tooth, and the film packet is assessed and bisected medially. The X-ray tube head is positioned at right angle to the bisecting line with the central ray of the X-ray beam aimed through the tooth apex. Vertical angulation of the $\mathrm{X}$ ray tube head is the angle formed by continuing the line of the central ray until it meets the occlusal plane. Horizontal angulation of the X-ray tube head depicts that the central ray should be aimed through the interproximal contact areas, to avoid overlapping the teeth. The horizontal angulation is therefore, determined by the shape of the arch and the position of the teeth. This technique can be performed either by using a film holder who helps in supporting the film packet in the patient's mouth or by asking the patient to support the film packet gently using either an index finger or thumb or by using a film holder to avoid irradiating the patient's fingers (John PR 1999).Focusing the $x$ ray beam to the imaginary bisector in bisecting angle technique may not be accurate from individual to individual, where as in paralleling technique it is easy to practice and maintain accuracy to even reproduce if film is without bending film and placing the film parallel to the long axis of the tooth.

Undergraduate students had reported to make more technical errors when they used bisecting-angle radiographic technique than the paralleling technique. The purpose of the study is to know the opinion regarding usage to intra oral Periapical radiographic techniques (Forsberg J et al, 1997).
According to Ibrahim et al in a cross-sectional study performed to compare the efficacies and errors of Paralleling technique and Bisecting angle technique when used for endodontic working length determination the results of the study revealed that significantly higher proportion of retake due to errors was found with bisecting angle technique (24.16\%), as compared to Paralleling technique $(10.83 \%)$. Thus, concluded that the paralleling technique produces less distortion and is less variable, which is similar to present study (Ibrahim 2013).

Forsberg and Rushton V.E reported that radiographs taken with holders who had a positioning arm to guide alignment, which were designed to allow patients to bite together, while the film was exposed, had a lower intolerance rate than the holders (Forsberg 1987, Rushton V.E 1994). There were a limited number of studies (Van Vorde\&Bjorndahl 1969, Forsberg 1987, Gound et al. 1994) in which the use of the paralleling technique has been compared with the bisecting angle technique for technical accuracy of endodontic working length films(Gound GT et al, 1994 Raoof, M. et al 2014) and present study being one among them.

Literature reveals that, use of film holders in endodontic practice ranges from $26.3 \%$ (Chandler \& Koshy 2002) to $41.7 \%$ of dentists (Saunders et al, 1999). Moreover, the routine use of film holders ranges from $21.6 \%$ (Saunders et al, 1999). Thus expanding use of film holders has been shown to have a relationship to those practitioners who use a rubber dam (Chandler \& Koshy 2002), those clinicians who are specialization in Endodontics (Chandler \&Koshy 2002) and also has a significant relationship to younger clinicians (Saunders et al.1999) to $26 \%$ (Chandler \&Koshy 2002). Each of these studies, however, has confirmed the superiority of the paralleling technique (Saunders WP et al, 1999 A c Chandler NP et al, 2002). This result is similar to present study.

Owing to image accuracy aspects, there is mixed opinion regarding a type of technique to be preferred, but most of them preferred paralleling technique followed by bisecting angle technique and other techniques. Other techniques preferred under these aspects were for Orthopantomograph (OPG), Computed tomography (CT) and Cone beam computed tomography (CBCT) reason may be due to the limitations of the IOPA in delineating the extent of the underlying pathology.

Owing to operator and exposure parameters, individuals in a present study favored bisecting angle technique more than paralleling technique. Study conducted by kazzi et al a comparative study of three radiographic techniques used for endodontic working length estimation reveal expertise in either of technique maintains less discomfort for operator, patient and also prevents retakes thus decreasing unnecessary exposure (Kazzi 2007).

Owing to other aspects the technique which is commonly advised forchildren and mentally challenged individuals were paralleling technique.

Aps J K M conducted a study to determine general dental practitioner's awareness of dental radiography, the results of this study showed that the awareness of dental radiography in Flanders regarding dentomaxillo-facial radiology is poor (JKM Aps 2010). However, the results of present study revealed that though there is knowledge regarding the different types of techniques among general practitioners, but lack of application in regular practice, decreases their ability to get more accurate diagnostic radiograph.

In the present study, paralleling technique showed better results in appreciation of details than the bisecting angle technique. It is important to develop the dental curriculum to ensure that both undergraduate and post-graduate students have the necessary competency when using these devices in clinical practice. There is still a great deal of work to be done to ameliorate the quality of radiographs and the knowledge and attitude of dental 
graduates regarding dentomaxillo-facial radiology. Paralleling technique being the most accurate in image accuracy should be emphasized to practice and needed to be modified in conditions where it is not feasible to deal with

\section{Graphs for four factors}

$\mathrm{X}$-axis denotes the percentage of individuals answering to particular questions

Y-axis denotes the 5 groups

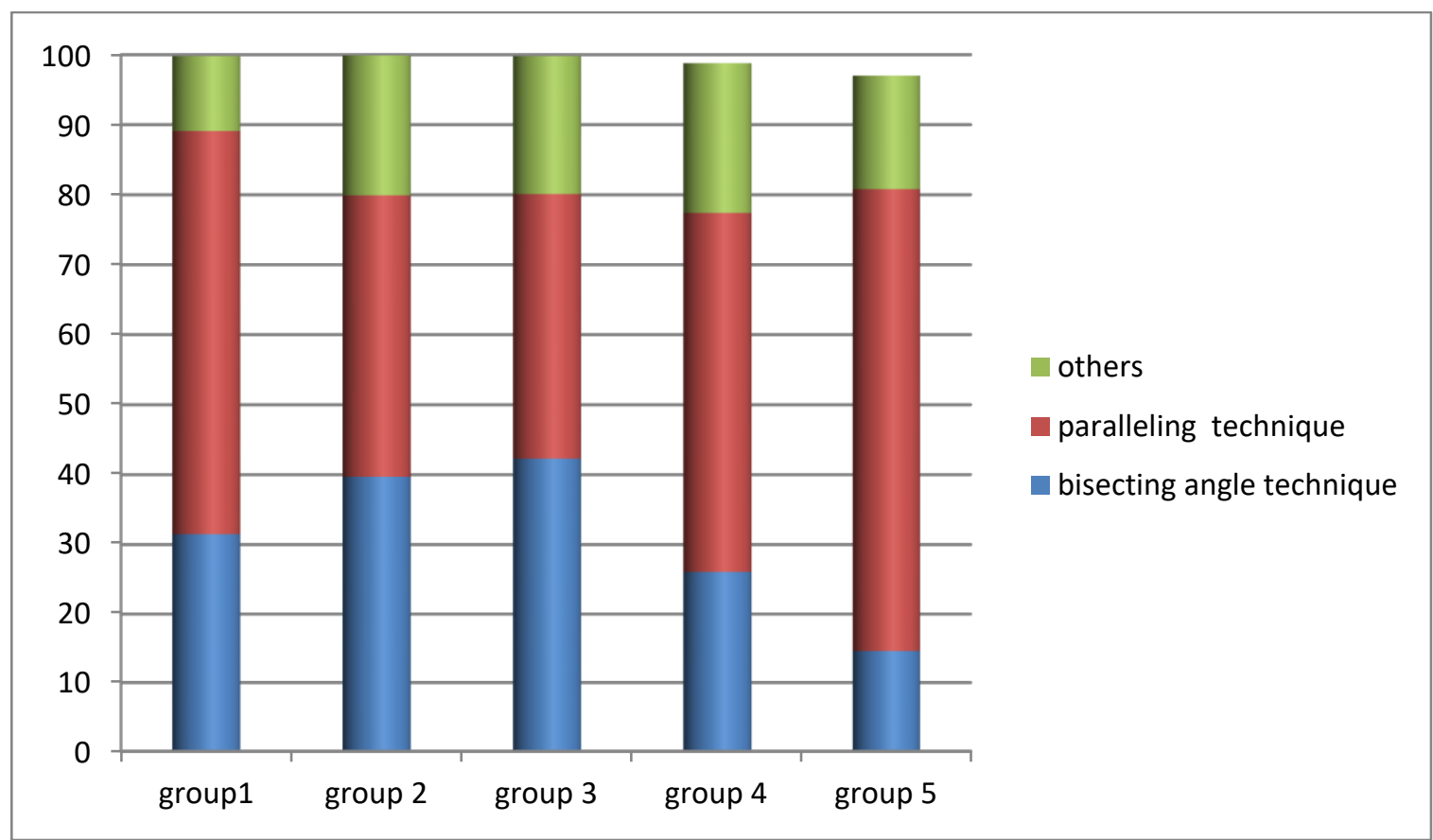

Graph 1: Comparison of Opinions- Regarding Questions under which Technique Is Better in Attaining Image Accuracy.

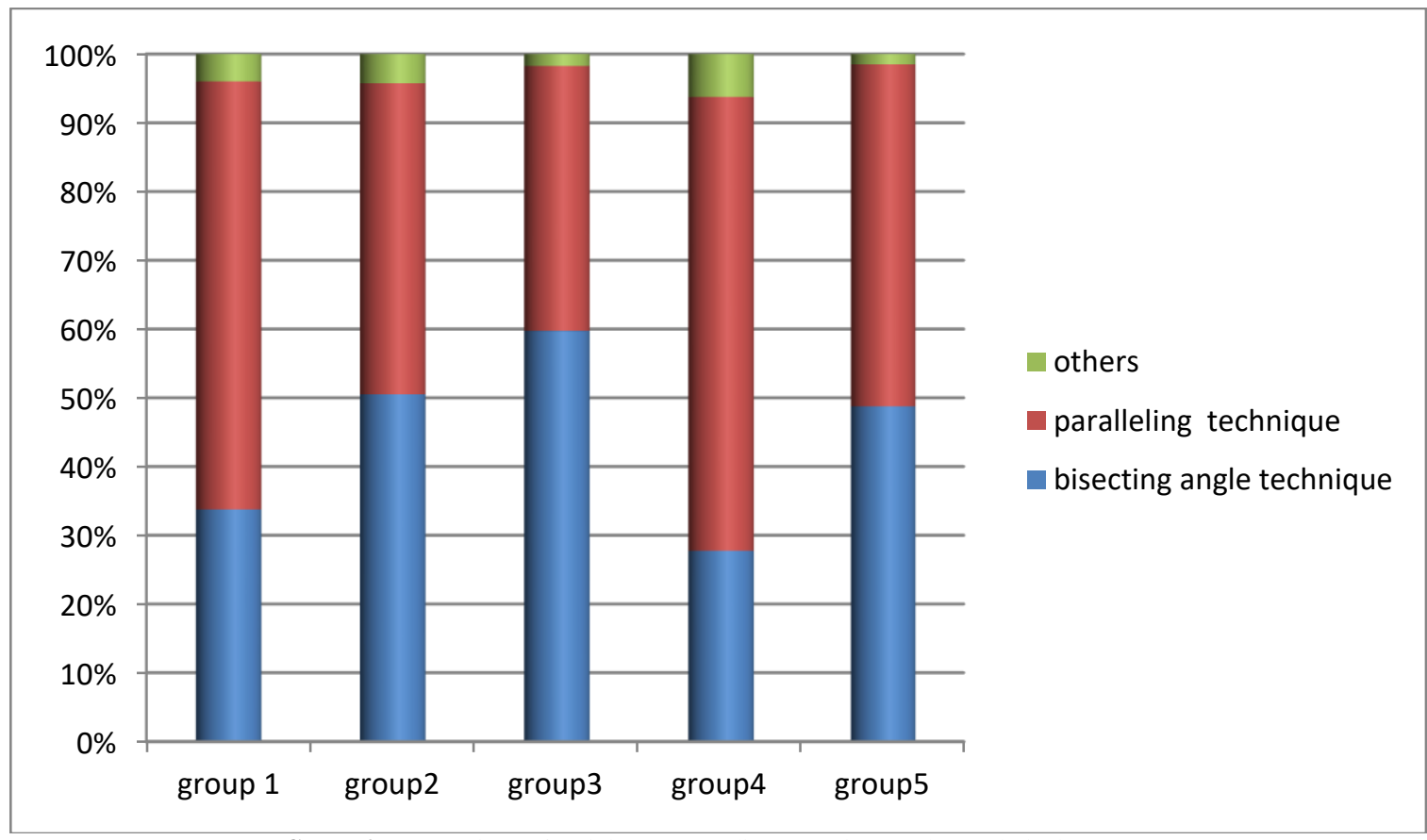

Graph 2: Comparison of Opinions -Regarding Questions under Technical Factors. 


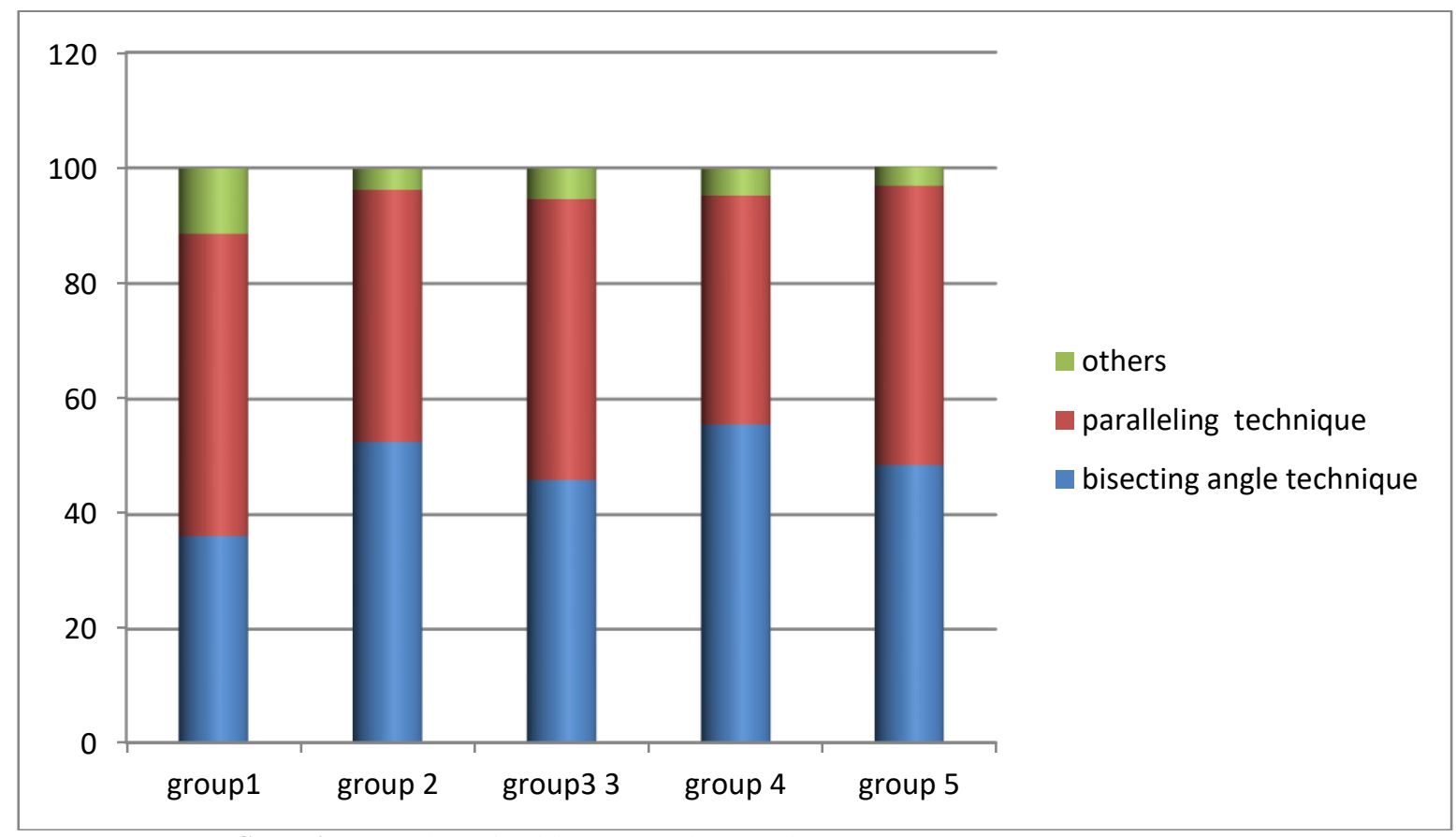

Graph 3: Comparison of Opinions -Regarding Questions under Operator and Exposure Factors.

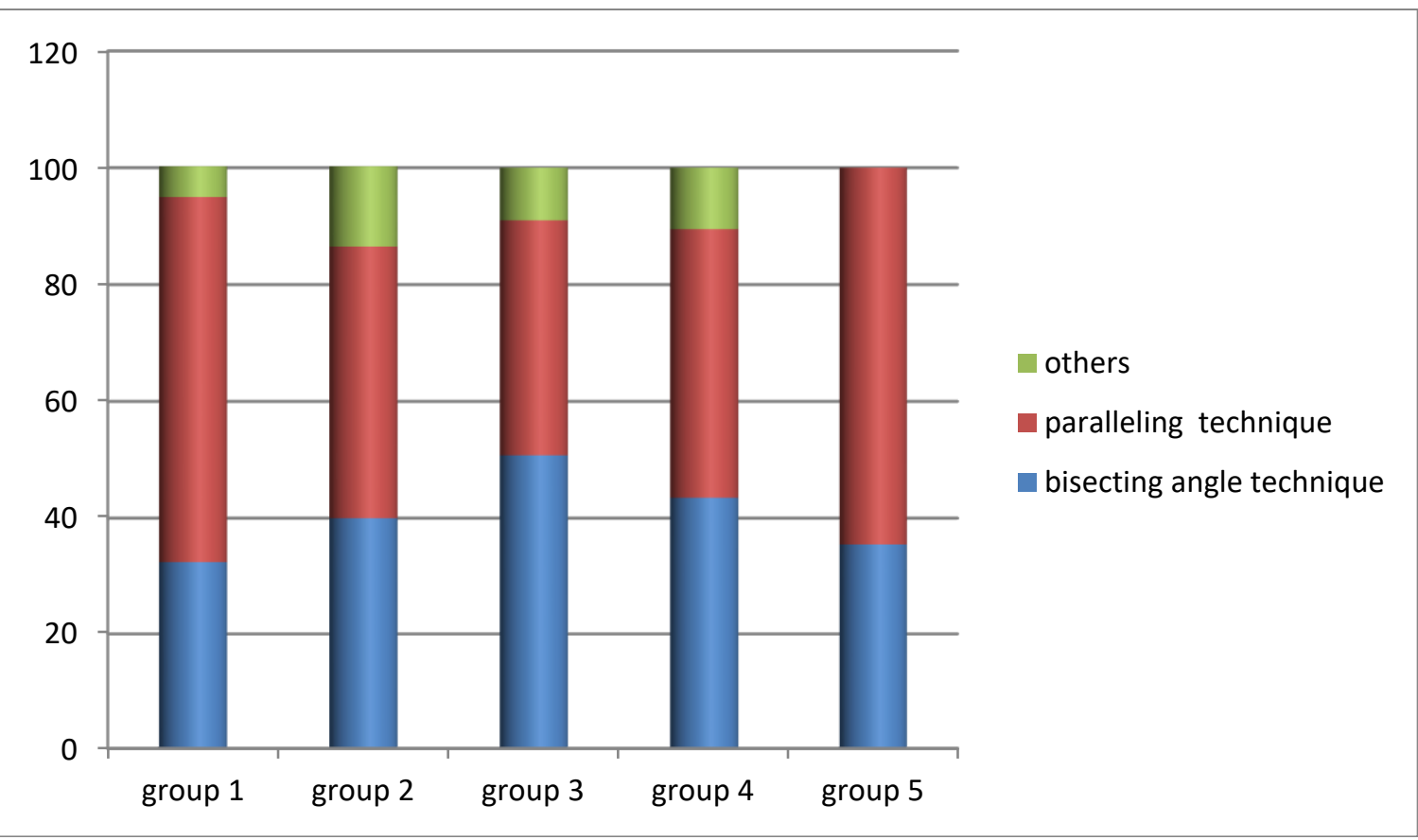

Graph 4: Comparison of Opinions - Regarding Questions under other Factors.

Graph 1: shows most of the individuals in all the groups opted in favour of paralleling technique

Graph 2: shows most of the individuals in all the groups opted in favour of paralleling technique

Graph 3: shows most of the individuals in all the groups opted in favour of paralleling technique and bisecting angle technique

Graph 4: shows most of the individuals in all the groups opted in favour of paralleling technique

\section{Conclusion}

Great work should have to be done to alleviate the quality of radiographs and the understanding and perspective of dental graduates regarding dentomaxillo facial radiology. The results of present study revealed though there is knowledge regarding the techniques, but lack of application decreases their ability to get more accurate diagnostic radiograph and benefiting the public. Radiographs exposed with a conventional film holder for the par- alleling technique will give a safe radiographic guidance and ought to be beneficial for public to reduce the exposure of the patients. Paralleling angle technique will give refinery, reproducibility more than bisecting angle technique for purpose of recording and analyzing. Usinga film holder and a beam guiding device an adequate result can be obtained without extensive clinical training. However, individual efforts to change, and gaining knowledge and practice make the undergraduate to have better knowledge on dental radiography.

\section{References}

[1] Bramanet CM, Berbert A (1974) A critical evaluation of some methods of determining tooth length. Journal of Oral Surgery, 37: 463. http://dx.doi.org/10.1016/0030-4220 (74)90122-4

[2] Ludlow JB, Mol A. Digital imaging. In: White SC, Pharoah MJ (eds). (2004) Oral radiology: Principles and interpretation (6th ed). St.Louis: Mosby. 109-35. 
[3] Sudhakar S (2014) Utility of Extra-Oral Aiming Device in Imaging Periapical Regions of Posterior Teeth .Journal of Clinical and Diagnostic Research, 8: 51-55.

[4] Jamdade AS (2014) Modified bisecting angle technique in eliminating zygomatic superimposition over apices of maxillary molars. Indian Journal of Dental Research, 25:521-6. http://www.ijdr.in/text.asp?2014/25/4/521/142560. https://doi.org/10.4103/0970-9290.142560.

[5] Whaites E (2002) Essentials of Dental Radiography and Radiology. 3rd ed. Edinburgh,Churchill Livingstone, 89-110.

[6] Bragger U (2005) Radiographic parameters: biological significance and clinical use. Journal of Periodontalogy, 39:7390.https://doi.org/10.1111/j.1600-0757.2005.00128.x.

[7] Langland OF, Langlais RP, Preece JW (2002) Principles of denta imaging. 2nd ed. Philadelphia, 91-97.

[8] John PR (1999) Essentials of Dental Radiology 1st Ed. New Delhi Jaypee brothers, 75-81.

[9] Forsberg J, Halse A (1997) Periapical radiolucencies as evaluated by bisecting-angle and paralleling radiographic techniques. International journal of endodontic, 30:115-23. https://doi.org/10.1046/j.1365-2591.1997.00059.x.

[10] Ibrahim (2013) Comparison of paralleling and bisecting angle techniques in endodontic working length radiography .Pakistan Oral \& Dental Journal, 33(1).

[11] Forsberg J (1987). Estimation of the root filling length with the paralleling and bisecting-angle techniques performed by undergraduate students. International Endodontic Journal, 20:282-286. https://doi.org/10.1111/j.1365-2591.1987.tb00628.x.

[12] Rushton V.E, Homer K (1994) A comparative study of radiographic quality with five periapical techniques in general dental practice. DentomaxillofacialRadiology,

$23: 37-$ 45.https://doi.org/10.1259/dmfr.23.1.8181658.

[13] Gound GT, Dubois L, Biggs SG (1994) Factors that affect rate of retakes for endodontic treatment radiographs. Journal of Oral Surgery Oral Medicine Oral Pathology, 77: 514-8. https://doi.org/10.1016/0030-4220(94)90234-8.

[14] Raoof, M., Heidaripour, M., Shahravan, A., Haghani, J., Afkham, A., Razifar, M., \&Mohammadizadeh, S (2014). General Dental Practitioners' Concept towards Using Radiography and ApexLocators in Endodontics. Iranian Endodontic Journal, 9(4): 277282.

[15] Saunders WP, Chesnutt IG, Saunders EM (1999) Factors influencing the diagnosis and management of the teeth with pulpal and periradicular disease by general dental practitioners. British Dental Journal, 548-54.

[16] A c Chandler NP, Koshy S (2002) Radiographic practices of dentists undertaking endodontics in New Zealand. Journal of Dento maxillofacial Radiology, 31: 317-21. https://doi.org/10.1038/sj.dmfr.4600717.

[17] Kazzi (2007) A comparative study of three periapical radiographic techniques for endodontic working length estimation. International Endodontic Journal, 40: 526-531. https://doi.org/10.1111/j.13652591.2007.01251.x

[18] JKM Aps (2010) Flemish general dental practitioner's knowledge of dental Radiology. DentomaxillofacialRadiology, 39(2):113-118. https://doi.org/10.1259/dmfr/52763613. 